\title{
O resgate de uma dívida: resenha do livro Escritos de Louis Le Guillant - da Ergoterapia à Psicopatologia do Trabalho ${ }^{1}$
}

\author{
Maria Elizabeth Antunes Lima ${ }^{2}$ \\ Departamento de Psicologia da Universidade Federal de Minas Gerais
}

E mbora defasado em relação a outros países, o campo da Saúde Mental e Trabalho no Brasil tem passado por considerável avanço, sobretudo no decorrer da última década. Vários grupos de pesquisa se consolidaram e as publicações se multiplicam, revelando uma crescente preocupação com um tema cuja importância é inegável. De fato, foi somente nos anos 80 que os pesquisadores brasileiros despertaram para a necessidade de se debruçar sobre um problema que, no entanto, já era ressentido e denunciado por algumas entidades de classe. $\mathrm{O}$ avanço rápido da disciplina só veio confirmar a existência de uma demanda social que, embora antiga, encontrava-se, até então, sem o devido respaldo acadêmico.

No entanto, ainda que o crescimento das pesquisas e das publicações sobre o assunto fosse incontestável, uma lacuna grave persistia: Louis Le Guillant, um teórico que teve um papel central na fundação dessa disciplina na França, permanecia praticamente ignorado em nosso país. Com exceção de um único artigo publicado há alguns anos, não tinha sido tomada, até agora, qualquer iniciativa no sentido de ampliar a divulgação de sua obra.

A coletânea com uma seleção cuidadosa dos seus textos, recentemente lançada pela Editora Vozes, representa um esforço no sentido de resgatar a dívida que temos para com esse autor. Do prefácio escrito por Yves Clot ao posfácio de Wanderley Codo, cujo título inspirou a autora desta resenha, fica patente a importância crucial dessa publicação no atual estágio da disciplina no Brasil.

O legado do autor é tão vasto quanto seu esforço no sentido de tratar a grande diversidade de problemas de seu tempo. Dentre os vários temas aos quais se dedicou, dois foram escolhidos para compor a coletânea: a Ergoterapia e a Psicopatologia do Trabalho. Dessa forma, o leitor poderá contar com uma ampla variedade de estudos que vão da perspectiva do trabalho como uma atividade favorável à saúde mental até aquela em que seu exercício pode ser fonte de sofrimento ou mesmo de transtornos mentais graves. Esse dado, por si só, já coloca em evidência um mérito de Le Guillant: ele estava ciente da complexidade do objeto sobre o qual se debruçava ao perceber nele essa dupla potencialidade e, portanto, ao constatar que, dependendo do seu modo de organização e das condições sob as quais é realizado, o trabalho pode atuar como um recurso terapêutico ou favorecer o adoecimento

Le Guillant foi um dos membros mais importantes do movimento da Psiquiatria Social, que emergiu na França logo após a Segunda Guerra Mundial. Dentro desse movimento, destacou-se entre os teóricos que, inspirados nos trabalhos de Georges Politzer, propunham que se entendesse a gênese da loucura, antes de tudo, como uma questão social.

1 Editora Vozes, Petrópolis, 2006.

2 Organizadora e apresentadora do livro resenhado. Esta é uma versão, ligeiramente modificada, da resenha publicada pela autora no Jornal Estado de Minas de 02/09/2006. 
Dessa forma, deu continuidade à visão dos transtornos mentais como um fenômeno ao qual só podemos ter acesso se seguirmos o caminho traçado pela psicossociologia, uma disciplina que permite situar o indivíduo, ao mesmo tempo, no meio em que vive e na sua história real.

Nesse sentido, ele aprofundou as discussões em torno da reinserção social de portadores de transtornos mentais graves, fazendo avançar o conhecimento das chamadas "terapêuticas ativas", tema que ocupa toda a primeira parte da coletânea. O trabalho inovador que desenvolveu com seus pacientes, à medida em que produzia bons resultados, revelava a ineficácia da prática comumente adotada pela instituição psiquiátrica de sua época, que permanecia, segundo ele, "pobre e equivocada por trás de sua segurança habitual". O tratamento que propunha, e que considerava como o único verdadeiramente eficaz, consistia no retorno gradual desses pacientes para o seu meio de origem. Portanto, muito mais do que uma simples reforma psiquiátrica, o que Le Guillant preconizava era a superação da ordem asilar, a única saída, segundo ele, para uma instituição cujas práticas desumanas, desde sua origem, a desqualificavam para qualquer esforço de humanização.

Ao propor medidas que iam além da revisão das práticas assistenciais comumente oferecidas aos pacientes no âmbito do hospital ou da criação de instituições extrahospitalares, nosso autor conquistou um lugar entre os precursores da luta anti-manicomial em seu país. E o que é mais importante: além de refletir sobre a necessidade de superar as formas tradicionais de tratamento, ele repensou o lugar da psiquiatria na sociedade, propondo que ela agisse na prevenção dos transtornos mentais em todos os lugares nos quais se manifestam e que empreendesse um esforço pedagógico junto à população a fim de reduzir as atitudes de rejeição que reforçam o isolamento dos doentes mentais.

A segunda parte da coletânea vem ampliar e enriquecer a discussão anterior, ao privilegiar o adoecimento e desvelar uma outra face do trabalho, dessa vez, favorecendo a emergência de transtornos mentais específicos. Ela contém uma rica variedade de estudos e ensaios referentes à contribuição de Le Guillant para o campo da Psicopatologia do Trabalho. Entre as diversas categorias profissionais que investigou, duas foram contempladas na coletânea brasileira, as telefonistas e as empregadas domésticas, pela relevância dos seus achados e pelo tratamento pertinente que foi dado às questões teórico-metodológicas. Ao estudar as primeiras, ele detectou um quadro que denominou de "neurose das telefonistas" (capítulo 1 da parte II), cada vez mais atual e freqüentemente identificado entre os profissionais do setor de teleatendimento, um dos que mais crescem no contexto da economia globalizada. O estudo com as empregadas domésticas, um clássico da disciplina, também não poderia faltar nessa publicação. Reunindo rigor e sensibilidade, Le Guillant nos revela com riqueza de detalhes o cotidiano da doméstica parisiense de sua época, surpreendentemente parecido com o que observamos na sociedade brasileira contemporânea. $O$ caráter patogênico dessa atividade tão próxima de cada um de nós e, ao mesmo tempo, tão pouco estudada e compreendida, está claramente demonstrado, ao mesmo tempo em que o autor nos oferece uma ilustração do método "pluridimensional". Assim, ele articula com maestria os dados qualitativos e os quantitativos, o singular e o coletivo, as informações advindas da literatura técnica sobre o assunto e aquelas obtidas na literatura em geral. ${ }^{3}$

Não poderia faltar também nessa parte da obra um artigo sobre a "fadiga nervosa" (capítulo 3), que é um quadro atribuído por Le Guillant aos processos de trabalho que se disseminavam na França de sua época, mas que tornou-se muito mais freqüente nas décadas posteriores em decorrência das maiores exigências de produtividade e da competição cada vez mais acirrada entre as empresas. O teórico francês conseguiu, portanto, perceber nas formas

3 Para enriquecer esse tópico, foi incluído um artigo de difícil acesso, publicado pelo autor na Revista Temps Modernes em 1963, no qual ele analisa um crime cometido em 1933 no interior da França por duas irmãs empregadas domésticas (capítulo 5, parte II). Esse crime, pelas suas características de extrema violência, tem sido objeto de diversas reflexões no meio acadêmico, além de ter inspirado alguns filmes, documentários e até uma conhecida peça teatral de Jean Genet, As criadas. Dentre essas produções, o artigo de Le Guillant se destaca pela fidelidade aos fatos, pela riqueza e pela pertinência de suas análises. 
de organização do trabalho do seu tempo os sinais ainda incipientes dessa patologia que assume, atualmente, um caráter epidêmico.

Mais especificamente no campo da clínica, foi escolhido o caso Marie L. (capítulo 6, parte II), considerado com razão por alguns dos estudiosos da obra de Le Guillant como o ponto máximo de sua trajetória. De fato, nosso autor propõe uma nova abordagem dos problemas de saúde em geral, inovando os processos de diagnóstico e tratamento através do "método biográfico". A história clínica de Marie L. representa, provavelmente, o momento em que ele conseguiu articular melhor as dimensões subjetiva e objetiva, o singular e o coletivo, escapando à visão dicotômica que prevalecia em seu meio e que jamais deixou de combater. Ao expor o caso, deixou claro que todo seu esforço consistia em compreender o adoecimento a partir da ultrapassagem das explicações "sumárias e insatisfatórias" a respeito de suas "causas sociais" ou "psicológicas". O que propunha, bem dentro do espírito politzeriano, era que se tentasse estabelecer possibilidades de compreensão e de intervenção no plano "do conhecimento prático do homem", levando sempre em conta a história dos pacientes, a partir de suas condições concretas de existência. O contexto psicológico deveria ser apreendido, segundo ele, de forma integrada com as condições de vida e ser concebido como o "reflexo no espírito do paciente das condições sociais e educativas, econômicas e ideológicas, ao mesmo tempo bem reais e particulares que ele viveu desde sua infância até o momento atual”. Finalmente, ele vai além das perspectivas reducionistas da psicogênese ou da sociogênese, ao dizer que seu propósito é o de "fazer aparecer no plano do conhecimento prático do homem, da história dos doentes e de suas condições concretas de existência, possibilidades de compreensão e de intervenção que ultrapassem a simples afirmação freqüentemente tão sumária e insatisfatória - de 'causas sociais' ou 'psicológicas' para as manifestações da patologia funcional".

Enfim, trata-se de um autor cujo valor já foi posto à prova do tempo, conquistando um lugar entre os clássicos de sua disciplina, graças à sensibilidade com a qual abordava cada tema, ao interesse especial que desenvolveu pela pesquisa e à perspicácia que lhe permitiu identificar os verdadeiros problemas a serem atacados. Os resultados que alcançou fizeram avançar o campo da Saúde Mental e Trabalho no seu país, devendo auxiliar, agora, os pesquisadores brasileiros na busca de respostas para um problema social que, infelizmente, só tende a agravar.

\section{Endereço para correspondência}

bethalima@terra.com.br 


\section{Cadernos de Psicologia Social do Trabalho}

\section{Pedido de assinatura e de exemplares avulsos}

Para fazer uma assinatura ou solicitar qualquer exemplar avulso, envie-nos a ficha abaixo preenchida e cheque nominal ao Instituto de Psicologia - USP. Por gentileza, escreva ou telefone para saber os valores atuais de cada exemplar ou da assinatura.

Centro de Psicologia Aplicada ao Trabalho

Av. Prof. Mello Moraes, 1721

Bloco D, sala 163

Cidade Universitária, São Paulo/ SP

05508-030

Endereço eletrônico: cpat@usp.br

\begin{tabular}{|l|l|c|c|}
\hline Quantidade & \multicolumn{1}{|c|}{ Pedido } & \multicolumn{1}{|c|}{ Valor $^{*}$} & \multicolumn{1}{|c|}{ Total } \\
\hline & volume 1 & esgotado & esgotado \\
\hline & volume 2 & & \\
\hline & volume 3/4 & & \\
\hline & volume 5 & & \\
\hline & volume 6 & & \\
\hline & $\begin{array}{l}\text { volume 7 } \\
\text { volume 8 }\end{array}$ & & \\
\hline & volume 9, número 1 & Total: R\$ \\
\hline & assinatura por dois anos (quatro exemplares) & & \\
\hline & & & \\
\hline
\end{tabular}

" Por favor, consultem-nos a respeito dos valores antes de fazer seus pedidos.

\begin{tabular}{|c|c|c|}
\hline Nome: & & \\
\hline Endereço: & & \\
\hline & & CEP: \\
\hline Cidade: & & Estado: \\
\hline Telefone: ( ) & E-mail: & \\
\hline Data: / / & Assinatura: & \\
\hline
\end{tabular}

